\title{
Managing anesthesia for cesarean section in obese patients: current perspectives
}

This article was published in the following Dove Press journal:

Local and Regional Anesthesia

16 August 2016

Number of times this article has been viewed

\author{
Agnes M Lamon \\ Ashraf S Habib \\ Department of Anesthesiology, Duke \\ University Medical Center, Durham, \\ NC, USA
}

\begin{abstract}
Obesity is a worldwide epidemic. It is associated with increased comorbidities and increased maternal, fetal, and neonatal complications. The risk of cesarean delivery is also increased in obese parturients. Anesthetic management of the obese parturient is challenging and requires adequate planning. Therefore, those patients should be referred to antenatal anesthetic consultation. Anesthesia-related complications and maternal mortality are increased in this patient population. The risk of difficult intubation is increased in obese patients. Neuraxial techniques are the preferred anesthetic techniques for cesarean delivery in obese parturients but can be technically challenging. An existing labor epidural catheter can be topped up for cesarean delivery. In patients who do not have a well-functioning labor epidural, a combined spinal epidural technique might be preferred over a single-shot spinal technique since it is technically easier in obese parturients and allows for extending the duration of the block as required. A continuous spinal technique can also be considered. Studies suggest that there is no need to reduce the dose of spinal bupivacaine in the obese parturient, but there is little data about spinal dosing in super obese parturients. Intraoperatively, patients should be placed in a ramped position, with close monitoring of ventilation and hemodynamic status. Adequate postoperative analgesia is crucial to allow for early mobilization. This can be achieved using a multimodal regimen incorporating neuraxial morphine (with appropriate observations) with scheduled nonsteroidal anti-inflammatory drugs and acetaminophen. Thromboprophylaxis is also important in this patient population due to the increased risk of thromboembolic complications. These patients should be monitored carefully in the postoperative period, since there is increased risk of postoperative complications in the morbidly obese parturients.
\end{abstract}

Keywords: obesity, neuraxial techniques, cesarean delivery

\section{Introduction}

Obesity is a global epidemic. It is estimated that over $50 \%$ of pregnant woman in the United States are overweight or obese. ${ }^{1}$ The World Health Organization, and the National Heart, Lung and Blood Institute use body mass index (BMI) to define normal weight as BMI $18.9-24.9 \mathrm{~kg} / \mathrm{m}^{2}$, overweight as BMI $25-29.9 \mathrm{~kg} / \mathrm{m}^{2}$, and obese as BMI $>30 \mathrm{~kg} /$ $\mathrm{m}^{2}{ }^{2}$ Although any BMI $>30 \mathrm{~kg} / \mathrm{m}^{2}$ is obese, three further classes can be described: BMI $30-34.9 \mathrm{~kg} / \mathrm{m}^{2}$ (obesity class 1 ), BMI $35-39.9 \mathrm{~kg} / \mathrm{m}^{2}$ (obesity class II), and BMI $>40$ $\mathrm{kg} / \mathrm{m}^{2}$ (obesity class III). ${ }^{3}$ Other nomenclature may be found in the literature including morbid obesity $\left(\right.$ BMI $\left.>40 \mathrm{~kg} / \mathrm{m}^{2}\right)$ and super obesity $\left(\mathrm{BMI}>50 \mathrm{~kg} / \mathrm{m}^{2}\right)$. There is no definition of obesity specific to pregnancy, and BMI classifications have limitations in certain populations such as those with advanced age, athletes, and in pregnancy. Therefore, in
Correspondence: Ashraf S Habib Department of Anesthesiology, Duke University Medical Center, Box 3094, Durham, NC 277I0, USA

Email habib00I@dm.duke.edu 
2009, the Institute of Medicine updated their recommendations for managing obesity in pregnancy. It is now recommended that obstetricians evaluate gestational weight gain based on prepregnancy BMI and gestational age. ${ }^{4}$

Although there are no racial, social, or economic boundaries that obesity does not cross, obesity is most prevalent among those with low socioeconomic status, low education status, and minority women. ${ }^{5}$ It is a multisystem disease with several associated comorbidities (Table 1). In addition to these comorbidities, obesity is associated with prolonged labor ${ }^{6}$ and with significant maternal, fetal, and neonatal complications (Table 2). The risk of cesarean delivery is increased in obese parturients, which is most relevant to this article. In a study involving 121,092 nulliparous women stratified by prepregnancy BMI, Tabet et $\mathrm{al}^{7}$ reported that the odds ratio ( $95 \%$ confidence interval) for cesarean delivery among overweight and obese women was $1.50(1.41,1.59)$ and 2.06 $(1.91,2.21)$ respectively. ${ }^{7}$ Similar findings were reported in other large cohorts. ${ }^{8,9}$

The fact that obesity is associated with an increased risk of death during pregnancy is most concerning. In a review of all pregnancy-related deaths in Wisconsin between 2006 and 2010, Schellpfeffer et $\mathrm{al}^{10}$ found that $76 \%$ of women who died were overweight or obese. ${ }^{10}$ Additionally, Main et $\mathrm{al}^{11}$ reviewed maternal-related deaths in California from 2002 to 2005 and found that women who died were more likely to be obese or morbidly obese, particularly women who died from thromboembolic events and cardiovascular disease. ${ }^{11}$ In the United Kingdom, the Confidential Enquiry into Maternal Deaths found that in the last three reports covering the years 2003-2013, 49\%-52\% of women who died were overweight or obese. ${ }^{12-14}$

Obesity is also a risk factor for anesthesia-related maternal mortality. Mhyre et $\mathrm{al}^{15}$ reviewed anesthesia-related deaths in Michigan between 1985 and 2003 and reported that six of eight women who died were obese. ${ }^{15}$ Similarly, the Confidential Enquiries into Maternal Deaths in the United Kingdom found that out of the 17 deaths directly attributed to anesthesia in the last three reports, six occurred in obese parturients. $^{12-14}$

The following sections discuss the preoperative, intraoperative, and postoperative management of cesarean delivery in the obese parturient.

\section{Anesthesia consultation and preoperative assessment}

Because of the significant risk of complications associated with obesity in pregnancy, both the American College of Obstetricians and Gynecologists $(\mathrm{ACOG})^{16}$ and the Royal
Table I Common comorbidities associated with obesity

\begin{tabular}{ll}
\hline Comorbidity & $\begin{array}{l}\text { Odds ratio } \\
\text { (95\% confidence interval) }\end{array}$ \\
\hline Type 2 diabetes & $12.41(9.03,17.06)$ \\
Hypertension & $2.42(1.59,3.67)$ \\
Coronary artery disease & $3.1(2.81,3.43)$ \\
Congestive heart failure & $1.78(1.07,2.95)$ \\
Pulmonary embolism & $3.51(2.61,4.73)$ \\
Stroke & $1.49(1.27,1.74)$ \\
Asthma & $1.78(1.36,2.32)$ \\
Gallbladder disease & $2.32(1.17,4.57)$ \\
Chronic back pain & $2.81(2.27,3.48)$ \\
\hline
\end{tabular}

Note: Data from a previous study. ${ }^{10}$

Table 2 Obstetric complications in the obese compared with the nonobese parturients

\begin{tabular}{|c|c|}
\hline Obstetric complication & $\begin{array}{l}\text { Odds ratio } \\
\text { ( } 95 \% \text { confidence interval) }\end{array}$ \\
\hline Gestational diabetes"II & $2.4(2.2,2.7)$ \\
\hline Hypertensive disorders ${ }^{\prime \prime \prime}$ & $3.3(2.7,3.9)$ \\
\hline Venous thromboembolism 112 & $9.7(3.1,30.8)$ \\
\hline Induction of labor ${ }^{1 / 3}$ & $\mathrm{I} .84(\mathrm{I} .53,2.2 \mathrm{I})$ \\
\hline Total cesarean delivery ${ }^{113}$ & $2.42(2.02,2.91)$ \\
\hline Emergency cesarean delivery ${ }^{113}$ & $2.15(1.78,2.58)$ \\
\hline Postpartum hemorrhage ${ }^{\prime \prime \prime}$ & $2.3(2.1,2.6)$ \\
\hline Wound infection $1 / 4$ & $2.24(1.91,2.64)$ \\
\hline Macrosomia $^{1 / 3}$ & $3.39(2.78,4.18)$ \\
\hline Shoulder dystocia ${ }^{115}$ & $2.9(1.4,5.8)$ \\
\hline Prematurity"I' & $1.2(1.1,1.4)$ \\
\hline Still birth 116 & $2.1(1.5,2.7)$ \\
\hline Neonatal death ${ }^{117}$ & $2.6(1.2,5.8)$ \\
\hline
\end{tabular}

College of Obstetricians and Gynaecologists (RCOG) in conjunction with the Centre for Maternal and Child Enquiries ${ }^{17}$ published guidelines recommending a multidisciplinary team approach when caring for the obese parturients. These include 1) preconception counseling, 2) assessing BMI for all parturients to screen for obesity, 3) monitoring BMI, 4) providing strict guidelines for prenatal weight gain, and 5) an anesthesia consultation in the third trimester for woman with a BMI $>40 \mathrm{~kg} / \mathrm{m}^{2}$. During this consultation, a comprehensive history and physical examination should be performed, with emphasis on the evaluation of the airway, as well as the cardiovascular and pulmonary systems. A frank discussion of the risks and benefits of different types of anesthesia should take place with the patients, including an explanation of the importance of neuraxial analgesia and anesthesia and the fact that neuraxial techniques might be technically difficult and time consuming; therefore, patients should be encouraged to request neuraxial analgesia early in labor. This consultation also provides an opportunity to order any further investigations that might be needed to optimize safety of the mother and baby and discuss delivery planning with the patient. 
Obesity is a risk factor for obstructive sleep apnea (OSA), which is characterized by repeated episodes of upper airway collapse, leading to hypoxemia and hypercarbia. OSA is associated with increased risk for hypertension, myocardial infarction, stroke, diabetes, and metabolic syndrome..$^{18,19}$ Louis et $\mathrm{al}^{20}$ found a fivefold increase of in-hospital death in parturients with OSA compared with those without OSA, even when adjusting for serious cardiovascular, renal, and metabolic conditions. The same authors previously reported an increased risk of hypertensive disorders of pregnancy, gestational diabetes, and pre-eclampsia in parturients with OSA. ${ }^{21}$ Although it is well known that OSA is a serious problem in pregnancy, there are currently no validated tools to screen parturients for OSA. A recent study found that none of the commonly used screening tools was predictive for OSA in the pregnant patient population; however, individual items within those tools such as BMI $>35 \mathrm{~kg} / \mathrm{m}^{2}$, falling asleep when speaking with someone, and a history of hypertension were significant predictors of OSA. ${ }^{22}$ Women who are deemed at risk for sleep apnea should be referred for a sleep study, and if OSA is diagnosed, treatment with continuous positive airway pressure (CPAP) should be initiated.

Cardiovascular disease is the leading cause of maternal death in the United States, and obesity is a risk factor for pregnancy-related cardiovascular mortality. ${ }^{23} \mathrm{~A} \mathrm{BMI}>30 \mathrm{~kg} /$ $\mathrm{m}^{2}$ is associated with a threefold higher risk of hypertension during pregnancy. ${ }^{24}$ Women with chronic or gestational hypertension should be medically optimized throughout pregnancy according to ACOG guidelines. ${ }^{25}$ During the anesthesia consultation, adequacy of blood pressure control should be ensured. Morbidly obese parturients are noted to have increased left atrial size, left ventricular thickness, interventricular septal thickness, and left ventricular mass. ${ }^{26}$ Any new onset of shortness of breath, decrease in exercise tolerance greater than expected for pregnancy, or new syncope or chest pain may warrant referral for a thirdtrimester echocardiogram to identify patients with poor ventricular function who may not tolerate the autotransfusion in the peripartum period.

Eley et $\mathrm{al}^{27}$ investigated the impact of an anesthesia consultation on anxiety, decisional conflict, and risk perception of chronic disease in obese parturients. The same questions were asked before and after the anesthesia consultation, and interestingly, the authors found significantly decreased decisional conflict scores and reduced anxiety after consultation. However, the consultation and discussion with the anesthesia provider did not increase the parturients' awareness of the risks of obesity in pregnancy. ${ }^{27}$

\section{Anesthetic technique for cesarean delivery}

Unless there is a contraindication, neuraxial anesthesia is the anesthetic technique of choice for cesarean delivery in all parturients in general, and in the obese parturient in particular. Both pregnancy and obesity are risk factors for a difficult airway and anesthesia-related maternal mortality. In the United States, Hawkins et a ${ }^{28}$ reported that pregnancy-related mortality ratio for deaths related to anesthesia was 1.2 per million live births for the period 1991-2002, which represents a decrease of $59 \%$ in the deaths for the period 1979-1990. Between 1985 and 1990, the relative risk (95\% confidence interval) of general anesthesia compared with neuraxial anesthesia for cesarean delivery was $16.7(12.9,21.8)$. This decreased to $6.7(3.0,14.9)$ in 1991-1996 and further to 1.7 $(0.6,4.6)$ in $1997-2002$. The estimated case fatality rate of general anesthesia during cesarean delivery decreased from 16.8 deaths per million general anesthetics for 1991-1996 to 6.5 deaths per million general anesthetics for 1997-2002. In contrast, the estimated case fatality rate of regional anesthesia during cesarean delivery increased slightly from 2.5 deaths per million regional anesthetics to 3.8 deaths per million regional anesthetics. Approximately two-thirds of deaths due to general anesthesia are caused by intubation or other induction problems such as aspiration, and advances in airway management have undoubtedly contributed to the reduction in anesthetic deaths associated with general anesthesia. Another important factor to consider is that regional anesthesia has become preferred and more widely used overall and for many high-risk parturients in particular, including those with morbid obesity. For instance, Tonidandel et al reported that general anesthesia was used for cesarean delivery in 3\% of cases in morbidly obese parturients in 2011-2012, compared with a rate of $24 \%$ in a previous study in the same institution in 1993. ${ }^{29,30}$

While the risk for difficult intubation is increased in the parturient compared with the general surgical population, obesity itself is associated with a further increase in risk. ${ }^{31-33}$ It is also associated with an increased difficultly in mask ventilation. ${ }^{34}$ This is related to the short neck, fat deposition in the neck and shoulders increasing the difficulty for optimal position for laryngoscopy, breast hypertrophy as well as enlarged tongue, and excessive palatal and pharyngeal soft tissues. Hood and Dewan ${ }^{30}$ reported an incidence of difficult intubation of $33 \%$ in morbidly obese parturients undergoing cesarean delivery who weighed $>136 \mathrm{~kg} .{ }^{30}$ Airway changes also occur during labor, with an increase in airway class from prelabor, ${ }^{35}$ further increasing the risk of confronting a difficult intubation in this patient population. 
The following section focuses on neuraxial anesthetic techniques for cesarean delivery. The general principles of general anesthesia in the morbidly obese parturient are summarized in Table 3.

\section{Technical considerations Monitoring equipment}

An appropriate sized blood pressure cuff for noninvasive blood pressure measurements should be used. The American Heart Association recommendations for appropriate sizing of blood pressure cuffs specify that the width and

Table 3 General anesthesia considerations in obese parturients

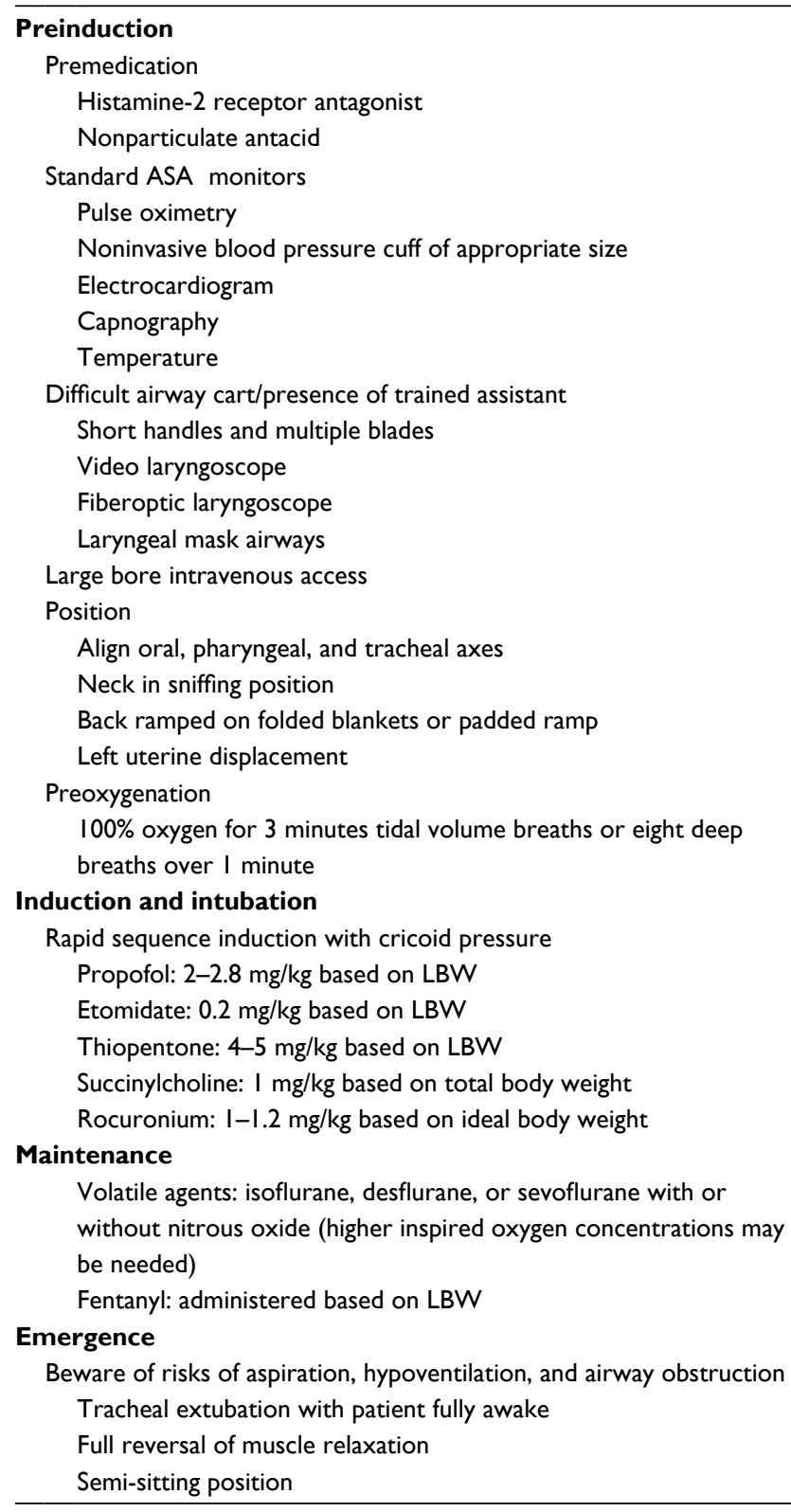

Note: Data from previous studies. ${ }^{42,118}$

Abbreviations: ASA, American Society of Anesthesiologists; LBW, lean body weight. length of the compression bladder should be equal to $40 \%$ and $80 \%$ of the upper arm circumference, respectively. ${ }^{36}$ Blood pressure measurement in the obese parturient presents challenges, not only because of the size of the upper arm, but also because of its conical shape, resulting in difficulties in fitting an appropriately sized blood pressure cuff, and therefore impacting the accuracy of the measurements obtained. ${ }^{37}$ For this reason, sometimes, a forearm blood pressure cuff is used. Although there is a good correlation between the upper arm and forearm blood pressure measurements, the latter exceed forearm measurements by an average of $10 \mathrm{mmHg} .{ }^{38}$ Recently, a conical blood pressure cuff for use on the forearm was developed to address the issues of proper sizing in obese patients and was reported to provide good agreement with arterial blood pressure measurements. ${ }^{39}$ In some morbidly obese parturients undergoing cesarean delivery such as those with cardiac disease, those at risk for bleeding or when there are significant difficulties in obtaining noninvasive blood pressure readings, invasive blood pressure monitoring might be appropriate.

\section{Spinal and epidural needles}

The distance to the epidural space is greater with increased BMI. ${ }^{40}$ Therefore, longer than standard spinal and epidural needles might be needed and should be available. However, in the majority of obese patients, neuraxial blocks can be performed successfully with standard length needles. ${ }^{41}$ Since the standard length needles are easier to manipulate and provide the anesthesiologist with better control compared with the longer ones, we recommend starting with the standard length needle and switching to the longer needle only if the epidural/intrathecal space could not be reached with the standard length needle. Performance of a pre-block ultrasound might also help estimate the distance to the epidural space.

\section{Acid aspiration prophylaxis}

Whether obese parturients have large gastric volume, low gastric $\mathrm{pH}$, or change in gastric emptying compared with nonobese parturients is unclear. ${ }^{42}$ However, gastroesophageal reflux and hiatal hernia are more common in obese compared with nonobese patients. ${ }^{43}$ Given that obesity is associated with an increased risk for difficult intubation, it is likely that obese parturients are at higher risk for aspiration. Routine acid aspiration prophylaxis should therefore be administered to all obese parturients undergoing cesarean delivery. In a recent meta-analysis, Paranjothy et al ${ }^{44}$ reported a significant reduction in the risk of intragastric $\mathrm{pH}<2.5$ with antacids, 
$\mathrm{H}_{2}$ antagonists, and proton pump inhibitors, when compared with placebo or no treatment. The combined use of antacids plus $\mathrm{H}_{2}$ antagonists was associated with a significant reduction in the risk of intragastric $\mathrm{pH}<2.5$ when compared with placebo or with antacids alone. Addition of metoclopramide might confer additional protection, ${ }^{45}$ but evidence is limited. ${ }^{44}$ A meta-analysis involving both obstetric and nonobstetric studies suggested that premedication with ranitidine was more effective than proton pump inhibitors in reducing the volume of gastric secretions and increasing gastric $\mathrm{pH}^{46}$ Ranitidine should be administered at least 60 minutes if given orally and 30 minutes if given intravenously, prior to cesarean delivery for optimum effect on gastric volume and $\mathrm{pH} .{ }^{47}$ However, there are no data to examine the association between reduced gastric acidity and the frequency of pulmonary aspiration, vomiting, morbidity, or mortality in obstetric patients who aspirate gastric contents. ${ }^{48}$ Administration can be initiated the evening before surgery in elective cases. Recent studies have suggested that the use of bedside gastric ultrasonography can be useful in assessing gastric contents during labor ${ }^{49}$ and prior to elective cesarean delivery. ${ }^{50}$

\section{Identification of the neuraxis: conventional approaches and ultrasonography}

Adequate staffing is needed to ensure that the patient is properly positioned for neuraxial anesthesia, and careful attention should be made that the patient remains centered on the operating table. Even with optimal positioning, identifying the epidural space can still be a challenge. Although neuraxial anesthesia can be performed in either a sitting or a lateral position, the sitting position is preferred in the obese. The sitting flexed position brings the epidural space closer to the skin and therefore the distance from the skin to the epidural space is shorter in this position compared with the lateral position. ${ }^{40}$ Furthermore, the obese parturients may have lateral pads of fat that sag and obscure the midline in the lateral position. Tape can be used to retract the pads of fat to the shoulders in the seated position to better visualize landmarks. It is also often difficult to identify the midline or palpate spinous processes in this patient population. ${ }^{51}$ Stiffler et $\mathrm{al}^{52}$ reported difficulty in palpating landmarks in $68 \%$ of obese nonpregnant patients compared with only $5 \%$ of those with a normal BMI. An additional advantage of the sitting position is that the prominence of the seventh cervical vertebra and gluteal cleft can be observed allowing for easier identification of the midline compared with the lateral position.
Other techniques have also been suggested to assist the anesthesiologist in identifying the midline. The larger gauge needle used for skin infiltration of local anesthetic may be used to identify the spinous process and interspaces. ${ }^{53}$ Marroquin et a $\mathrm{l}^{54}$ found that $77 \%$ of morbidly obese parturients provided useful information on the position of the needle during epidural placement and their input on laterality may be used for direction.

Ultrasonography can also be useful in identifying the midline, as well as estimating the depth to the epidural space. Balki et $\mathrm{al}^{55}$ found a strong correlation between the depth to the epidural space measured by the epidural needle and that estimated by ultrasound in obese parturients. ${ }^{55}$ However, there was a trend to underestimate the actual needle depth with ultrasound as the depth to the epidural space increased, likely due to increased soft tissue compression by the ultrasound probe in women with a high BMI. Sahin et $\mathrm{al}^{56}$ also found that prepuncture ultrasound reduced the number of attempts at spinal anesthesia in obese parturients undergoing cesarean delivery. Although image quality might not be optimal in the obese due to the thickness of the subcutaneous tissue, ${ }^{57}$ there is evidence that prepuncture ultrasound is useful to decrease the need for needle redirection during epidural placement and reduce replacement of failed catheters. ${ }^{55}$ A recent study suggested that the quality of imaging for prepuncture ultrasound might be better with the paramedian sagittal oblique plane compared with the transverse median plane in obese parturients. ${ }^{58}$

\section{Antibiotic prophylaxis}

ACOG recommends prophylactic antibiotics for all cesarean deliveries within 1 hour of skin incision. ${ }^{59}$ A Cochrane review found significant decrease in wound complications, endometritis, and infectious complications when prophylactic antibiotics were administered, regardless of the degree of urgency of the cesarean section. ${ }^{60}$ The optimum prophylactic antibiotic dosing in obese women is not clear. A study by Pevzner et $\mathrm{al}^{61}$ showed that a 2-g dose of cefazolin administered 30-60 minutes prior to cesarean delivery in obese (BMI 30-39.9 $\mathrm{kg} / \mathrm{m}^{2}$ ) or morbidly obese (BMI $\geq 40 \mathrm{~kg} / \mathrm{m}^{2}$ ) patients failed to achieve targeted minimum inhibitory concentrations in $20 \%$ and $33 \%$ of patients, respectively, at the time of skin incision and in $20 \%$ and $40 \%$ of patients at the time of incision closure. ${ }^{61}$ In fact, the Clinical Practice Guidelines for Antibiotic Prophylaxis in Surgery recommend a dose of $3 \mathrm{~g}$ of cefazolin before cesarean delivery in women weighing over $120 \mathrm{~kg} .{ }^{62}$ However, a study evaluating 20 obese patients who were randomized to receive 2 or $4 \mathrm{~g}$ of cefazolin found higher 
blood and tissue levels with the $4 \mathrm{~g}$ dose, but all collected subcutaneous and myometrial tissue samples had antibiotic concentrations above the minimum inhibitory concentration, and no surgical site infections or endometritis were reported. ${ }^{63}$ A recent retrospective study compared surgical site infections in morbidly obese women undergoing cesarean delivery who received 2 or $3 \mathrm{~g}$ of cefazolin preoperatively and also found no difference in surgical site infections between the two regimens. ${ }^{64}$

\section{Choice of neuraxial technique}

Different neuraxial techniques to consider are a single-shot spinal, continuous spinal, epidural, or a combined spinal epidural (CSE) technique.

\section{Single-shot spinal anesthesia}

Single-shot spinal anesthesia provides a fast onset, reliable, and dense neuroblockade, providing excellent operative conditions and high level of patient comfort, therefore minimizing the need for supplemental analgesics, which has benefits in the morbidly obese parturients with OSA and potentially difficult airway. ${ }^{65}$ There are however two limitations to the use of single-shot spinal anesthesia in the morbidly obese parturients. The first limitation relates to the inability to extend the duration of the block with a single-shot spinal technique. Given the increased duration needed to position the morbidly obese parturient on the operative table and the often prolonged duration of surgery in this patient population, ${ }^{66}$ a continuous technique is preferred to confer the ability to extend the duration of the neuraxial block and avoid the need to induce general anesthesia with its associated risks if the duration of surgery outlasts the duration of the spinal block. The second issue relates to the ease of performing the neuraxial block. Most often, 25-27 gauge pencil point spinal needles are used in the obstetric population to decrease the risk of postdural puncture headache (PDPH). ${ }^{67}$ The use of those small gauge needles might however be technically challenging in the morbidly obese parturients with excessive adipose tissue in the lumbar region, since the introducer used will be relatively short in this situation. Identifying the epidural space with a larger gauge Tuohy needle is easier to perform in an obese patient. The larger Tuohy needle would then act as an ideal introducer for the small gauge spinal needle allowing for location of the intrathecal space as part of a needle through needle CSE technique. In fact, a recent study reported that fewer attempts were needed to establish spinal anesthesia in the morbidly obese parturients with a CSE technique compared with a single-shot spinal technique. ${ }^{68}$

\section{Continuous neuraxial techniques}

The available options for a continuous neuraxial technique include the use of epidural catheters, spinal catheters, a CSE technique, or a double catheter technique.

\section{Epidural anesthesia}

A well-functioning labor epidural catheter can be topped up to achieve surgical anesthesia for cesarean delivery. Epidural analgesia represents the optimal method for pain relief during labor and should be administered early to the morbidly obese parturient, given the increased risks for macrosomia, shoulder dystocia, and cesarean delivery. It is very important to regularly assess the analgesia provided by the epidural catheter during labor, since a poorly functioning labor epidural catheter requiring frequent top-up doses may fail to provide adequate surgical anesthesia ${ }^{69}$; therefore, such catheters should be replaced early to reduce the risk of failure to achieve adequate surgical anesthesia if a cesarean delivery is needed.

The density of an epidural neuraxial block is in general less than that following an intrathecal block; therefore, epidural catheters are not commonly used as a de novo technique for cesarean delivery except in situations where it is desired to achieve a slower sympathetic block by slow titration of the local anesthetic through the epidural catheter to establish the required surgical level. This may be critical in some patients requiring a stable systemic vascular tone, such as those with cardiac disease. Slow titration of the epidural also decreases the risk of a high neuraxial block that would require emergent intubation, which is a feared complication in the morbidly obese, and therefore might be preferred by some providers in this patient population. Lastly, an epidural catheter may be used postoperatively for pain control.

\section{CSE anesthesia}

CSE anesthesia offers many of the benefits of the epidural catheter and single-shot spinal technique in that it provides a dense spinal anesthetic with the flexibility of a continuous technique. ${ }^{66}$ In addition, as previously mentioned, a needle through needle CSE technique is easier to perform in this patient population compared with a single-shot spinal anesthesia and therefore, is the technique of choice for elective cesarean delivery in the obese and morbidly obese parturients. If there is concern about an excessive block causing severe hypotension or respiratory compromise in the morbidly obese parturient, a lower spinal dose may be given and the anesthetic level titrated up using epidural saline (epidural volume expansion technique) or local anesthetic through 
the epidural catheter. However, the technique of epidural volume expansion might be unpredictable ${ }^{70}$ and has not been specifically investigated in the morbidly obese parturient. One concern with the CSE technique relates to the fact that the epidural catheter is untested and might fail to provide adequate anesthesia if the spinal block wears off and there is a need to use the epidural catheter intraoperatively. However, most studies suggest that the failure rate of an epidural catheter inserted as part of a needle through needle CSE technique is lower than that placed as part of an epidural only technique, since obtaining cerebrospinal fluid (CSF) through the spinal needle indirectly confirms the correct positioning of the epidural needle..$^{71,72}$

\section{Continuous spinal anesthesia}

Continuous spinal anesthesia allows slow titration of intrathecal local anesthetic to establish a dense block to the desired level while closely monitoring hemodynamics and respiratory status, thus decreasing the risk of a high spinal block, which can be disastrous in this patient population. ${ }^{73}$ The continuous technique also allows the provider to extend the duration of the block and provide adequate anesthesia for lengthy surgeries. This technique has been recommended by some to use in emergency situations in the obese parturient since it may be technically easier to identify the subarachnoid space with a large Tuohy needle than with a spinal needle and therefore perform the block quicker. ${ }^{41}$ Despite the advantages of this technique in the morbidly obese parturient, its routine use is limited by the risk of PDPH, since the block is performed with a large gauge Tuohy needle. However, some authors have suggested that obesity might have a protective effect against the development of PDPH. ${ }^{74}$ Possible explanations for the protective nature of obesity include the elevated intraabdominal pressure secondary to a large pannus reducing CSF leak and the fact that engorged veins and epidural fat may decrease any pressure difference between the epidural and subarachnoid space. ${ }^{75}$ Additionally, a magnetic resonance imaging study reported that obese patients have less CSF volume compared with nonobese patients. ${ }^{76}$ While a recent retrospective study by Miu et $\mathrm{al}^{77}$ failed to show a difference in the incidence of PDPH between BMI $<30 \mathrm{~kg} / \mathrm{m}^{2}$ and BMI $>30 \mathrm{~kg} / \mathrm{m}^{2}$ groups, a larger study by Peralta et $\mathrm{al}^{78}$ suggests that obesity $\left(\mathrm{BMI}>31.5 \mathrm{~kg} / \mathrm{m}^{2}\right.$ ) may be protective against the development of PDPH. On the other hand, another recent retrospective analysis by Franz et $\mathrm{al}^{79}$ suggest that the risk of PDPH following dural puncture with a 17-18 gauge Tuohy needle is only reduced in those with BMI $>50 \mathrm{~kg} / \mathrm{m}^{2}$. While continuous spinal anesthesia for cesarean delivery can be established using a 22-24 gauge catheter over the needle technique to reduce the risk of PDPH, the risk of failure and need for supplemental analgesia has been reported to range from $9 \%$ to $24 \% .{ }^{80,81}$ The technique has also not been specifically studied in morbidly obese patients.

\section{Double catheter technique}

Because of a larger pannus, the surgeons might decide to perform the cesarean delivery via a high supraumbilical vertical midline incision. With this incision, the morbidly obese patients may have impaired ventilation in the postoperative period secondary to pain and diaphragmatic splinting. Two reports described the use of a double catheter technique in super obese parturients who had a cesarean delivery through a vertical supraumbilical incision. McDonnell and Paech ${ }^{82}$ described the use of a lumbar CSE technique for intraoperative anesthesia and a low thoracic epidural catheter for postoperative analgesia in a super obese parturient with a BMI of $76 \mathrm{~kg} / \mathrm{m}^{2}$. More recently, Polin et $\mathrm{al}^{73}$ also reported using a double catheter technique in three super obese women (BMI $73-95 \mathrm{~kg} / \mathrm{m}^{2}$ ) undergoing vertical midline incisions for elective cesarean sections. A low thoracic epidural catheter was placed at T10-T12 and subsequently, a second lumbar continuous spinal catheter was placed. The authors reported titrating the spinal catheter to safely achieve the desired block height without compromising hemodynamics or respiratory function. The thoracic epidural catheter was used for postoperative analgesia. ${ }^{73}$ Interestingly, in one of those cases, adequate anesthesia for the upper end of the skin incision could only be achieved intraoperatively after dosing the thoracic epidural catheter.

\section{Transfer and positioning on the operating table}

The weight limits of the operating table should be checked to ensure that it can accommodate morbidly obese parturients. The use of table extenders should also be considered as appropriate, and pressure areas should be adequately padded. Special equipment for moving the patients might be needed, such as air-assisted mattresses (eg, HoverMatt ${ }^{\circledR}$, HoverTech International, Bethlehem, PA, USA), and staff should be trained in the use of such equipment.

Obese parturients should be positioned in a ramped position with left uterine displacement. This can be achieved by using folded blankets, pillows, a specifically designed padded ramp or by manipulating the operating room table. The aim should be to horizontally align the external auditory meatus and the sternal notch to optimize conditions for tracheal intubation if needed and to improve hemodynamic 
and respiratory parameters in the morbidly obese parturient. ${ }^{83}$ Care should be taken to secure the patients to the operating table first and to then initiate left uterine displacement promptly. Acute cardiovascular collapse has been previously reported in two obese patients after assuming the supine position. $^{84}$

The obstetrician might ask to perform cephalad retraction of the large panniculus to allow for a Pfannenstiel incision. Such retraction however might compromise the patient's ventilation and could result in hypotension. In fact, a case of intraoperative fetal death was reported in a morbidly obese parturient, who received epidural anesthesia, as a result of protracted hypotension following powerful cephalad retraction of the panniculus. ${ }^{85}$ Therefore, careful monitoring of ventilatory and circulatory status is crucial following retraction of the panniculus. Some perform vertical and cephalad suspension of the panniculus to reduce the risk of hypotension and hypoxemia. ${ }^{86}$ Commercially available devices are also used to retract the panniculus (eg, traxi ${ }^{\mathrm{TM}}$, Clinical Innovations, Murray, UT, USA), but there are no data evaluating those devices.

\section{Dosage of intrathecal local anesthetic}

It is known that the dose of intrathecal bupivacaine is reduced in pregnant compared with nonpregnant patients, ${ }^{87}$ due to factors such as enhanced spread of intrathecal local anesthetic due to the mechanical effect of epidural venous engorgement or alteration of the permeability of neural tissue to local anesthetics as a result of the hormonal changes in pregnancy. ${ }^{88}$ It is debated whether the local anesthetic dose should be further reduced in the obese parturient. Magnetic resonance imaging studies have confirmed a reduced lumbar CSF volume in the obese as well as an inverse correlation between the lumbar CSF volume and the cephalad extent of the block. ${ }^{3,76}$ This decreased CSF volume in the obese parturient is thought to result from caval compression by the gravid uterus and abdominal panniculus causing engorgement of epidural veins and increased abdominal pressure displacing soft tissue through the intervertebral foramina. This led to concerns about exaggerated spread of the spinal block in the obese parturient if the spinal dose is not reduced with the risk of a high spinal requiring emergency endotracheal intubation in a parturient with a potentially difficult airway and a significant aspiration risk. In fact, some reviews suggest a spinal dose reduction in the morbidly obese parturient. ${ }^{41,89,90}$ Clinical studies however do not support these concerns. Two independent studies found no correlation between height, weight, or BMI and the extent of spinal anesthesia, when a standard dose of bupivacaine $12 \mathrm{mg}$ was used for cesarean delivery in term parturients. ${ }^{91,92}$ However, the morbidly obese were not specifically studied in those trials. In a study estimating the dose requirements for bupivacaine in obese and nonobese parturients, Lee et $\mathrm{al}^{87}$ reported that the $95 \%$ effective dose (ED95) was similar in the two groups. Carvalho et al also found no difference in the ED50 and ED95 of hyperbaric spinal bupivacaine for cesarean delivery in morbidly obese parturients as compared with those estimated in a previous study using the same methodology in nonobese parturients. ${ }^{93,94}$ Therefore, current data do not support a reduction in the spinal dose of hyperbaric bupivacaine in the obese parturient. However, data on the spread of spinal block in the super obese parturient is limited. A retrospective study at our institution suggested that there was no risk of exaggerated spinal spread in the obese compared with the nonobese parturient except in those with BMI over $50 \mathrm{~kg} / \mathrm{m}^{2}{ }^{95}$

\section{Postoperative care Postoperative complications}

There is an increased risk of complications postoperatively in the obese. These include urinary tract infection, wound infection, wound dehiscence, peripheral nerve injury, hemorrhage, deep vein thrombosis, pulmonary embolism, atelectasis, pneumonia, respiratory depression, myocardial infarction, and maternal death. ${ }^{41}$

Respiratory depression in particular is a feared complication in the morbidly obese. In a report on maternal mortality in Michigan, Mhyre et al ${ }^{15}$ found that all anesthesia-related maternal deaths from hypoventilation or airway obstruction occurred during emergence and postanesthesia care with obesity recognized as a risk factor for these complications. ${ }^{15}$ It is well known that obesity is a risk factor for OSA. The American Society of Anesthesiologists (ASA) has issued practice guidelines for perioperative management of patients with OSA. While those guidelines do not specifically apply to the parturient, they highlight the increased risk of a difficult airway, place emphasis on regional anesthetic techniques to eliminate the need for systemic opioids, as well as introduce recommendations on postoperative analgesia including the use of opioid sparing strategies and avoidance of a background infusion with the use of intravenous opioid patient-controlled analgesia for pain control. ${ }^{96}$

\section{Analgesia}

The importance of adequate postoperative analgesia in the morbidly obese cannot be overstated as early mobilization reduces the risk of thromboembolic and pulmonary complications. Neuraxial morphine has been shown to provide superior analgesia to intravenous or oral opioids after cesarean delivery, although it is associated with an increased 
incidence of pruritus and nausea. ${ }^{97,98}$ There is however a concern that obese parturients might be at a higher risk for neuraxial morphine-induced respiratory depression, but the data are limited. Studies in women undergoing cesarean delivery have reported an incidence ranging from $0 \%$ to $0.9 \%$ following neuraxial morphine administration. ${ }^{99} \mathrm{~A}$ large retrospective study performed at our institution of 5,036 women who received neuraxial morphine for postcesarean analgesia found no cases of respiratory depression defined as a need for naloxone administration or rapid response team involvement for the management of respiratory depression. The study population included 2,283 obese (class I and II) and 886 morbidly obese (class III) parturients. ${ }^{100}$ We therefore continue to use neuraxial morphine in this patient population with appropriate monitoring for 24 hours according to the newly released guidelines from the ASA and the American Society of Regional Anesthesia and Pain Medicine. ${ }^{101}$ Intravenous opioid patient-controlled analgesia can be given to patients who did not receive neuraxial morphine, but would likely be associated with more sedation and possibly an increased risk for respiratory depression.

A multimodal analgesic regimen including regular dosing of acetaminophen and nonsteroidal anti-inflammatory drugs can optimize postoperative analgesia and decrease opioid consumption and should be prescribed routinely unless contraindicated. Local anesthetic techniques might also be helpful in this patient population. Transversus abdominis plane block improves postoperative analgesia in patients who do not receive intrathecal morphine, but not in those who received intrathecal morphine. ${ }^{102}$ It therefore reduces pain scores and analgesic consumption in patients who received a general anesthetic and those who did not receive long-acting neuraxial opioids but provides minimal - if any - benefit in patients who have received neuraxial morphine. However, it must be remembered that this block provides analgesia only for incisional pain and not visceral pain, and therefore, the resultant analgesia is inferior to that of neuraxial morphine. Furthermore, it might be technically challenging in the morbidly obese parturient. ${ }^{42,103}$ It can also be used as a rescue analgesic modality for those who continue to experience severe incisional pain despite a multimodal analgesic regimen. ${ }^{104}$ Local anesthetic wound infiltration has also been found to be effective at reducing postoperative analgesic consumption in women undergoing cesarean delivery and might be helpful in the morbidly obese parturient, but data are limited about the efficacy of this technique in women receiving neuraxial morphine. ${ }^{105}$ Patient-controlled epidural analgesia could also be used for postoperative analgesia, but might delay patient mobilization. ${ }^{106}$
Considerations regarding postoperative analgesia for breast-feeding women

When considering the potential risk to the neonate from exposure to medications excreted in breast milk, it is important to assess the amount of medication excreted in breast milk and the therapeutic effect on the infant. The relative infant dose represents one of the most useful parameters for assessing lactation risk. It is the absolute infant drug dose expressed as a percentage of the maternal dose normalized by weight. A breast milk concentration $<10 \%$ of the weight-normalized maternal dose has been considered arbitrarily as a safe level of exposure. ${ }^{107}$ The relative infant dose of commonly used analgesics in displayed in Table 4.

\section{Thromboprophylaxis}

Venous thromboembolism is a leading cause of maternal mortality. ${ }^{108,109}$ In the United Kingdom, a decline in maternal mortality from thromboembolism in the 2000s was attributed to better recognition of patients at risk and increased use of thromboprophylaxis..$^{12}$ However, in the most recent confidential enquiries report covering the years 2011-2013, venous thromboembolism was again the leading cause of direct maternal death. ${ }^{14}$ Obesity is a risk factor and is well represented in cases of maternal mortality from thromboembolism. For instance, $53 \%$ of women who died from venous thromboembolism in the most recent report were overweight or obese. While numerous guidelines exist for thromboprophylaxis in pregnancy, significant differences in the recommendations for thromboprophylaxis following cesarean delivery exist between the RCOG, ACOG, and American College of Chest Physicians as seen in Table 5. The most aggressive guidelines, especially in regard to thromboprophylaxis in obese women, are those of the RCOG, where all obese women will receive low molecular weight heparin. According to the American College of Chest Physicians guidelines, obesity is a minor risk factor, but in cases

Table 4 Relative infant dose of some analgesic agents

\begin{tabular}{ll}
\hline Analgesic agent & Relative infant dose (\%) \\
\hline Acetaminophen & 8.81 \\
lbuprofen & 0.65 \\
Naproxen & 3.3 \\
Celecoxib & 0.3 \\
Ketorolac & 0.2 \\
Hydromorphone & $<1$ \\
Hydrocodone & 2.4 \\
Morphine & $9-35$ \\
Oxycodone & 3.5 \\
Gabapentin & 6.5 \\
\hline
\end{tabular}

Notes: Relative infant dose is calculated by dividing the infant's dose via milk (in $\mathrm{mg} /$ $\mathrm{kg} / \mathrm{day}$ ) by the mother's dose (in $\mathrm{mg} / \mathrm{kg} /$ day). Data from a previous study. ${ }^{107}$ 
Table 5 Different guidelines for thromboprophylaxis in the parturient

American College of Chest Physicians ${ }^{119}$
Recommendation: Low molecular weight heparin for one major or
$\geq 2$ minor risk factors (mechanical prophylaxis if contraindications to
pharmacologic prophylaxis)
Major risk factors
Cesarean delivery with $\geq 1,000 \mathrm{~mL}$ postpartum hemorrhage
Immobility $>7$ days antepartum
History of venous thromboembolism
Medical comorbidities: sickle-cell disease, systemic lupus
erythematosus, heart disease
Thrombophilia: antithrombin deficiency, Factor V Leiden,
prothrombin G202IOA
Preeclampsia with fetal growth restriction
Blood transfusion
Postpartum Infection
Minor risk factors
Multiple pregnancy
Obesity BMI $>30$ kg/m ${ }^{2}$
Emergency cesarean section
Smoking $>10$ cigarettes/day
Fetal growth restriction
Thrombophilia: protein C or protein S deficiency
Preeclampsia
Royal College of Obstetricians and Gynaecologists
Recommendation: Assess risk factors to decide high, intermediate, or
lower risk
Risk factors
High risk (low molecular weight heparin for at least 6 weeks)
High-risk thrombophilia
Low-risk thrombophilia with a family history

Intermediate risk (low molecular weight heparin for at least 10 days) Cesarean delivery in labor $\mathrm{BMI} \geq 40 \mathrm{~kg} / \mathrm{m}^{2}$

Readmission or prolonged admission ( $\geq 3$ days) postpartum Any postpartum surgical procedure except for perineal repair High-risk medical comorbidities: Systemic lupus erythematosus, cancer, heart or lung disease, inflammatory conditions, sickle-cell disease, nephrotic syndrome, IV drug user

Other risk factors (treat as intermediate risk if 2 or more, if $<2$ factors consider as lower risk, early mobilization and avoid dehydration)

Obesity: BMI $\geq 30 \mathrm{~kg} / \mathrm{m}^{2}$

Gross varicose veins

Elective cesarean delivery

Family history of venous thromboembolism

Advanced maternal age ( $>35$ years)

Immobility such as paraplegia

Parity $\geq 3$

Current smoking

Preeclampsia

Multiple pregnancy

Cesarean delivery

Postpartum hemorrhage $>1,000 \mathrm{~mL}$ or blood transfusion

\section{Labor $>24$ hours \\ Preterm delivery \\ Stillbirth}

American College of Obstetricians and Gynecologists ${ }^{121}$

Recommendation I: Perioperative mechanical thromboprophylaxis for all women undergoing cesarean delivery

Recommendation 2: Low molecular weight heparin for any of the following

History of venous thromboembolism

Family history of venous thromboembolism and a thrombophilia

High-risks thrombophilias

Abbreviations: BMI, body mass index; IV, intravenous.

of an emergency cesarean delivery, all obese women should receive pharmacologic thromboprophylaxis. The ACOG guidelines do not have recommendations specific for obese parturients. It is important that institutional protocols are developed to provide adequate thromboprophylaxis in this high-risk patient population.

\section{Summary}

- The prevalence of obesity is increasing, and it is associated with significant comorbidities and increased obstetric, neonatal, surgical, and postoperative complications

- Antepartum anesthetic consultation should be performed to evaluate comorbidities, counsel patients, and plan for care

- A continuous neuraxial technique is the anesthetic technique of choice for cesarean delivery in the morbidly obese parturients

- Adequate postoperative analgesia and thromboprophylaxis are critical in the postoperative period

- Morbidly obese parturients are at high risk for OSA; therefore, they should be carefully monitored for postoperative hypoxemia resulting from airway obstruction and/or respiratory depression in the postoperative period

\section{Disclosure}

The authors report no conflicts of interest in this work.

\section{References}

1. Ogden CL, Carroll MD, Kit BK, Flegal KM. Prevalence of obesity among adults: United States, 2011-2012. NCHS Data Brief. 2013; (131):1-8.

2. Obesity: preventing and managing the global epidemic. Report of a WHO consultation. World Health Organ Tech Rep Ser. 2000;894:i-xii, $1-253$.

3. Carpenter RL, Hogan QH, Liu SS, Crane B, Moore J. Lumbosacral cerebrospinal fluid volume is the primary determinant of sensory block extent and duration during spinal anesthesia. Anesthesiology. 1998; 89(1):24-29.

4. Institute of Medicine, National Research Council Committee to Reexamine IOMPWG. The National Academies Collection: Reports funded by National Institutes of Health. In: Rasmussen KM, Yaktine AL, editors. Weight Gain During Pregnancy: Reexamining the Guidelines. Washington (DC): National Academies Press (US); 2009. 
5. Raghuwanshi M, Kirschner M, Xenachis C, Ediale K, Amir J. Treatment of morbid obesity in inner-city women. Obes Res. 2001;9(6):342-347.

6. Kominiarek MA, Chauhan SP. Obesity before, during, and after pregnancy: a review and comparison of five national guidelines. Am J Perinatol. 2016;33(5):433-441.

7. Tabet M, Flick LH, Tuuli MG, Macones GA, Chang JJ. Prepregnancy body mass index in a first uncomplicated pregnancy and outcomes of a second pregnancy. Am J Obstet Gynecol. 2015;213(4):548.e1-548.e7.

8. Dempsey JC, Ashiny Z, Qiu CF, Miller RS, Sorensen TK, Williams MA Maternal pre-pregnancy overweight status and obesity as risk factors for cesarean delivery. J Matern Fetal Neonatal Med. 2005;17(3):179-185.

9. Dietz PM, Callaghan WM, Morrow B, Cogswell ME. Population-based assessment of the risk of primary cesarean delivery due to excess prepregnancy weight among nulliparous women delivering term infants. Matern Child Health J. 2005;9(3):237-244.

10. Schellpfeffer MA, Gillespie KH, Rohan AM, Blackwell SP. A review of pregnancy-related maternal mortality in Wisconsin, 2006-2010. WMJ. 2015;114(5):202-207.

11. Main EK, McCain CL, Morton CH, Holtby S, Lawton ES. Pregnancyrelated mortality in California: causes, characteristics, and improvement opportunities. Obstet Gynecol. 2015;125(4):938-947.

12. Cantwell R, Clutton-Brock T, Cooper G, et al. Saving mothers' lives: reviewing maternal deaths to make motherhood safer: 2006-2008. The eighth report of the confidential enquiries into maternal deaths in the United Kingdom. BJOG. 2011;118(Suppl 1):1-203.

13. Lewis G. The Confidential Enquiry into Maternal and Child Health (CEMACH). Saving mother's lives: reviewing maternal deaths to make motherhood safer - 2003-2005. The seventh report on confidential enquiries into maternal deaths in the United Kingdom. CEMACH, London, UK; 2007.

14. Knight M, Tuffnell D, Kenyon S, Shakespeare J, Gray R, Kurinczuk J, editors; on behalf of MBRRACE-UK. Saving Lives, Improving Mothers Care-Surveillance of Maternal Deaths in the UK 2011-13 and Lessons Learned to Inform Maternity Care from the UK and Ireland Confidential Enquiries into Maternal Deaths and Morbidity 2009-13. Oxford: National Perinatal Epidemiology Unit, University of Oxford; 2015.

15. Mhyre JM, Riesner MN, Polley LS, Naughton NN. A series of anesthesia-related maternal deaths in Michigan, 1985-2003. Anesthesiology. 2007;106(6):1096-1104.

16. American College of Obstetricians and Gynecologists. ACOG Committee opinion no. 549: obesity in pregnancy. Obstet Gynecol. 2013;121(1):213-217.

17. Modder J, Fitzsimons KJ. The Centre for Maternal and Child Enquiries (CMACE) and the Royal College of Obstetricians and Gynaecologists (RCOG). CMACE/RCOG Joint Guideline. Management of Women with Obesity in Pregnancy; 2010.

18. Fung AM, Wilson DL, Barnes M, Walker SP. Obstructive sleep apnea and pregnancy: the effect on perinatal outcomes. J Perinatol. 2012;32(6):399-406.

19. Tantrakul V, Sirijanchune P, Panburana P, et al. Screening of obstructive sleep apnea during pregnancy: differences in predictive values of questionnaires across trimesters. J Clin Sleep Med. 2015;11(2):157-163.

20. Louis JM, Mogos MF, Salemi JL, Redline S, Salihu HM. Obstructive sleep apnea and severe maternal-infant morbidity/mortality in the United States, 1998-2009. Sleep. 2014;37(5):843-849.

21. Louis JM, Auckley D, Sokol RJ, Mercer BM. Maternal and neonatal morbidities associated with obstructive sleep apnea complicating pregnancy. Am J Obstet Gynecol. 2010;202(3):261.e1-261.e5.

22. Lockhart EM, Ben Abdallah A, Tuuli MG, Leighton BL. Obstructive sleep apnea in pregnancy: assessment of current screening tools. Obstet Gynecol. 2015;126(1):93-102.

23. Hameed AB, Lawton ES, McCain CL, et al. Pregnancy-related cardiovascular deaths in California: beyond peripartum cardiomyopathy. Am J Obstet Gynecol. 2015;213(3):379.e1-379.e10.

24. Weiss JL, Malone FD, Emig D, et al. Obesity, obstetric complications and cesarean delivery rate - a population-based screening study. Am J Obstet Gynecol. 2004;190(4):1091-1097.
25. American College of Obstetricians and Gynecologists. ACOG Practice Bulletin No. 125: chronic hypertension in pregnancy. Obstet Gynecol. 2012;119(2 Pt 1):396-407.

26. Veille JC, Hanson R. Obesity, pregnancy, and left ventricular functioning during the third trimester. Am J Obstet Gynecol. 1994;171(4):980-983.

27. Eley VA, Donovan K, Walters E, Brijball R, Eley DS. The effect of antenatal anaesthetic consultation on maternal decision-making, anxiety level and risk perception in obese pregnant women. Int J Obstet Anesth. 2014;23(2):118-124.

28. Hawkins JL, Chang J, Palmer SK, Gibbs CP, Callaghan WM. Anesthesia-related maternal mortality in the United States: 1979-2002. Obstet Gynecol. 2011;117(1):69-74.

29. Tonidandel A, Booth J, D'Angelo R, Harris L, Tonidandel S. Anesthetic and obstetric outcomes in morbidly obese parturients: a 20-year follow-up retrospective cohort study. Int J Obstet Anesth. 2014;23(4): 357-364.

30. Hood DD, Dewan DM. Anesthetic and obstetric outcome in morbidly obese parturients. Anesthesiology. 1993;79(6):1210-1218

31. Juvin P, Lavaut E, Dupont H, et al. Difficult tracheal intubation is more common in obese than in lean patients. Anesth Analg. 2003;97(2): 595-600.

32. Shiga T, Wajima Z, Inoue T, Sakamoto A. Predicting difficult intubation in apparently normal patients: a meta-analysis of bedside screening test performance. Anesthesiology. 2005;103(2):429-437.

33. Lundstrøm LH, Møller AM, Rosenstock C, Astrup G, Wetterslev J. High body mass index is a weak predictor for difficult and failed tracheal intubation: a cohort study of 91,332 consecutive patients scheduled for direct laryngoscopy registered in the Danish Anesthesia Database. Anesthesiology. 2009;110(2):266-274.

34. Kheterpal S, Han R, Tremper KK, et al. Incidence and predictors of difficult and impossible mask ventilation. Anesthesiology. 2006;105(5): 885-891.

35. Kodali BS, Chandrasekhar S, Bulich LN, Topulos GP, Datta S Airway changes during labor and delivery. Anesthesiology. 2008; 108(3):357-362.

36. Pickering TG, Hall JE, Appel LJ, et al. Recommendations for blood pressure measurement in humans and experimental animals: Part 1: blood pressure measurement in humans: a statement for professionals from the Subcommittee of Professional and Public Education of the American Heart Association Council on High Blood Pressure Research. Hypertension. 2005;45(1):142-161.

37. Umana E, Ahmed W, Fraley MA, Alpert MA. Comparison of oscillometric and intraarterial systolic and diastolic blood pressures in lean, overweight, and obese patients. Angiology. 2006;57(1):41-45.

38. Pierin AM, Alavarce DC, Gusmao JL, Halpern A, Mion D Jr. Blood pressure measurement in obese patients: comparison between upper arm and forearm measurements. Blood Press Monit. 2004;9(3):101-105.

39. Hersh LT, Sesing JC, Luczyk WJ, Friedman BA, Zhou S, Batchelder PB. Validation of a conical cuff on the forearm for estimating radial artery blood pressure. Blood Press Monit. 2014;19(1):38-45.

40. D'Alonzo RC, White WD, Schultz JR, Jaklitsch PM, Habib AS. Ethnicity and the distance to the epidural space in parturients. Reg Anesth Pain Med. 2008;33(1):24-29.

41. Soens MA, Birnbach DJ, Ranasinghe JS, van Zundert A. Obstetric anesthesia for the obese and morbidly obese patient: an ounce of prevention is worth more than a pound of treatment. ActaAnaesthesiol Scand. 2008;52(1):6-19.

42. Habib AS, D’Angelo R. Obesity. In: Chestnut D, editor. Chestnut's Obstetric Anesthesia. Vol 5. Philadelphia (PA): Elsevier; 2014:1141-1153.

43. Eslick GD. Gastrointestinal symptoms and obesity: a meta-analysis Obes Rev. 2012;13(5):469-479.

44. Paranjothy S, Griffiths JD, Broughton HK, Gyte GM, Brown HC, Thomas J. Interventions at caesarean section for reducing the risk of aspiration pneumonitis. Cochrane Database Syst Rev. 2014;2:Cd004943.

45. Goldberg ME, Norris MC, Larijani GE, Marr AT, Seltzer JL. Does atropine inhibit the effect of metoclopramide pretreatment on gastric contents in the morbidly obese population? Anesthesiology. 1987;67(3A):A289. 
46. Clark K, Lam LT, Gibson S, Currow D. The effect of ranitidine versus proton pump inhibitors on gastric secretions: a meta-analysis of randomised control trials. Anaesthesia. 2009;64(6):652-657.

47. Escolano F, Sierra P, Ortiz JC, Cabrera JC, Castano J. The efficacy and optimum time of administration of ranitidine in the prevention of the acid aspiration syndrome. Anaesthesia. 1996;51(2):182-184.

48. Practice Guidelines for Obstetric Anesthesia: An Updated Report by the American Society of Anesthesiologists Task Force on Obstetric Anesthesia and the Society for Obstetric Anesthesia and Perinatology. Anesthesiology. 2016;124(2):270-300.

49. Bataille A, Rousset J, Marret E, Bonnet F. Ultrasonographic evaluation of gastric content during labour under epidural analgesia: a prospective cohort study. Br J Anaesth. 2014;112(4):703-707.

50. Arzola C, Perlas A, Siddiqui NT, Carvalho JC. Bedside gastric ultrasonography in term pregnant women before elective cesarean delivery: a prospective cohort study. Anesth Analg. 2015;121(3):752-758.

51. Ellinas EH, Eastwood DC, Patel SN, Maitra-D'Cruze AM, Ebert TJ. The effect of obesity on neuraxial technique difficulty in pregnant patients: a prospective, observational study. Anesth Analg. 2009;109(4):1225-1231.

52. Stiffler KA, Jwayyed S, Wilber ST, Robinson A. The use of ultrasound to identify pertinent landmarks for lumbar puncture. Am J Emerg Med. 2007;25(3):331-334

53. Maitra AM, Palmer SK, Bachhuber SR, Abram SE. Continuous epidural analgesia for cesarean section in a patient with morbid obesity. Anesth Analg. 1979;58(4):348-349.

54. Marroquin BM, Fecho K, Salo-Coombs V, Spielman FJ. Can parturients identify the midline during neuraxial block placement? J Clin Anesth. 2011;23(1):3-6.

55. Balki M, Lee Y, Halpern S, Carvalho JC. Ultrasound imaging of the lumbar spine in the transverse plane: the correlation between estimated and actual depth to the epidural space in obese parturients. Anesth Analg. 2009;108(6):1876-1881.

56. Sahin T, Balaban O, Sahin L, Solak M, Toker K. A randomized controlled trial of preinsertion ultrasound guidance for spinal anaesthesia in pregnancy: outcomes among obese and lean parturients: ultrasound for spinal anesthesia in pregnancy. J Anesth. 2014;28(3):413-419.

57. Carvalho JC. Ultrasound-facilitated epidurals and spinals in obstetrics. Anesthesiol Clin. 2008;26(1):145-158,vii-viii.

58. Sahota JS, Carvalho JC, Balki M, Fanning N, Arzola C. Ultrasound estimates for midline epidural punctures in the obese parturient: paramedian sagittal oblique is comparable to transverse median plane. Anesth Analg. 2013;116(4):829-835.

59. American College of Obstetricians and Gynecologists. ACOG Practice Bulletin No. 120: Use of prophylactic antibiotics in labor and delivery. Obstet Gynecol. 2011;117(6):1472-1483.

60. Smaill FM, Grivell RM. Antibiotic prophylaxis versus no prophylaxis for preventing infection after cesarean section. Cochrane Database Syst Rev. 2014;10:Cd007482.

61. Pevzner L, Swank M, Krepel C, Wing DA, Chan K, Edmiston CE Jr. Effects of maternal obesity on tissue concentrations of prophylactic cefazolin during cesarean delivery. Obstet Gynecol. 2011;117(4):877-882.

62. Bratzler DW, Dellinger EP, Olsen KM, et al. Clinical practice guidelines for antimicrobial prophylaxis in surgery. Am J health Syst Phar. 2013;70(3):195-283.

63. Stitely M, Sweet M, Slain D, et al. Plasma and tissue cefazolin concentrations in obese patients undergoing cesarean delivery and receiving differing pre-operative doses of drug. Surg Infect (Larchmt). 2013;14(5):455-459.

64. Ahmadzia HK, Patel EM, Joshi D, et al. Obstetric surgical site infections: 2 grams compared with 3 grams of cefazolin in morbidly obese women. Obstet Gynecol. 2015;126(4):708-715.

65. Riley ET, Cohen SE, Macario A, Desai JB, Ratner EF. Spinal versus epidural anesthesia for cesarean section: a comparison of time efficiency, costs, charges, and complications. Anesthesia Analg 1995;80(4):709-712.

66. Butwick A, Carvalho B, Danial C, Riley E. Retrospective analysis of anesthetic interventions for obese patients undergoing elective cesarean delivery. J Clin Anesth. 2010;22(7):519-526.
67. Tsen LC, Hepner DL. Needles used for spinal anesthesia. Expert Rev Med Devices. 2006;3(4):499-508.

68. Ross VH, Dean LS, Thomas JA, Harris LC, Pan PH. A randomized controlled comparison between combined spinal-epidural and singleshot spinal techniques in morbidly obese parturients undergoing cesarean delivery: time for initiation of anesthesia. Anesth Analg. 2014;118(1):168-172.

69. Bauer ME, Kountanis JA, Tsen LC, Greenfield ML, Mhyre JM. Risk factors for failed conversion of labor epidural analgesia to cesarean delivery anesthesia: a systematic review and meta-analysis of observational trials. Int J Obstet Anesth. 2012;21(4):294-309.

70. McNaught AF, Stocks GM. Epidural volume extension and low-dose sequential combined spinal-epidural blockade: two ways to reduce spinal dose requirement for caesarean section. Int J Obstet Anesth. 2007;16(4):346-353.

71. Miro M, Guasch E, Gilsanz F. Comparison of epidural analgesia with combined spinal-epidural analgesia for labor: a retrospective study of 6497 cases. Int J Obstet Anesth. 2008;17(1):15-19.

72. Pan PH, Bogard TD, Owen MD. Incidence and characteristics of failures in obstetric neuraxial analgesia and anesthesia: a retrospective analysis of 19,259 deliveries. Int J Obstet Anesth. 2004;13(4): 227-233.

73. Polin CM, Hale B, Mauritz AA, et al. Anesthetic management of super-morbidly obese parturients for cesarean delivery with a double neuraxial catheter technique: a case series. Int $J$ Obstet Anesth. 2015;24(3):276-280.

74. Faure E, Moreno R, Thisted R. Incidence of postdural puncture headache in morbidly obese parturients. Reg Anesth. 1994;19(5):361-363.

75. Vallejo MC. Anesthetic management of the morbidly obese parturient. Curr Opin Anaesthesiol. 2007;20(3):175-180.

76. Hogan QH, Prost R, Kulier A, Taylor ML, Liu S, Mark L. Magnetic resonance imaging of cerebrospinal fluid volume and the influence of body habitus and abdominal pressure. Anesthesiology. 1996;84(6):1341-1349.

77. Miu M, Paech MJ, Nathan E. The relationship between body mass index and post-dural puncture headache in obstetric patients. Int J Obstet Anesth. 2014;23(4):371-375.

78. Peralta F, Higgins N, Lange E, Wong CA, McCarthy RJ. The relationship of body mass index with the incidence of postdural puncture headache in parturients. Anesth Analg. 2015;121(2):451-456.

79. Franz AM, Jia SY, Bahnson HT, Habib AS. The effect of second stage pushing and body mass index on post-dural puncture headache. American Society of Anesthesiologists Annual Meeting; 2015: A1081.

80. Alonso E, Gilsanz F, Gredilla E, Martinez B, Canser E, Alsina E. Observational study of continuous spinal anesthesia with the catheter-over-needle technique for cesarean delivery. Int JObstet Anesth. 2009;18(2):137-141.

81. Dresner M, Pinder A. Anaesthesia for caesarean section in women with complex cardiac disease: 34 cases using the Braun Spinocath spinal catheter. Int J Obstet Anesth. 2009;18(2):131-136.

82. McDonnell NJ, Paech MJ. The management of a super morbidly obese parturient delivering twins by caesarean section. Anaesth Intensive Care. 2007;35(6):979-983.

83. Artuso D, Wayne M, Cassaro S, Cerabona T, Teixeira J, Grossi R. Hemodynamic changes during laparoscopic gastric bypass procedures. Arch Surg. 2005;140(3):289-292.

84. Tsueda K, Debrand M, Zeok SS, Wright BD, Griffin WO. Obesity supine death syndrome: reports of two morbidly obese patients. Anesth Analg. 1979;58(4):345-347.

85. Hodgkinson R, Husain FJ. Caesarean section associated with gross obesity. Br J Anaesth. 1980;52(9):919-923.

86. Whitty RJ, Maxwell CV, Carvalho JC. Complications of neuraxial anesthesia in an extreme morbidly obese patient for cesarean section. Int J Obstet Anesth. 2007;16(2):139-144.

87. Lee Y, Balki M, Parkes R, Carvalho JC. Dose requirement of intrathecal bupivacaine for cesarean delivery is similar in obese and normal weight women. Rev Bras Anestesiol. 2009;59(6):674-683.

88. Saravanakumar K, Rao SG, Cooper GM. Obesity and obstetric anaesthesia. Anaesthesia. 2006;61(1):36-48. 
89. Roofthooft E. Anesthesia for the morbidly obese parturient. Curr Opin Anaesthesiol. 2009;22(3):341-346.

90. Brodsky JB, Lemmens HJ. Regional anesthesia and obesity. Obes Surg. 2007;17(9):1146-1149.

91. Norris MC. Height, weight, and the spread of subarachnoid hyperbaric bupivacaine in the term parturient. Anesth Analg. 1988;67(6):555-558.

92. Hartwell BL, Aglio LS, Hauch MA, Datta S. Vertebral column length and spread of hyperbaric subarachnoid bupivacaine in the term parturient. Reg Anesth. 1991;16(1):17-19.

93. Carvalho B, Collins J, Drover DR, Atkinson Ralls L, Riley ET. ED(50) and $\operatorname{ED}(95)$ of intrathecal bupivacaine in morbidly obese patients undergoing cesarean delivery. Anesthesiology. 2011;114(3):529-535.

94. Ginosar Y, Mirikatani E, Drover DR, Cohen SE, Riley ET. ED50 and ED95 of intrathecal hyperbaric bupivacaine coadministered with opioids for cesarean delivery. Anesthesiology. 2004;100(3):676-682.

95. Einhorn LM, Akushevich I, Habib AS. Intrathecal bupivacaine dose for cesarean delivery is not reduced in obese compared to non-obese parturients. American Society of Anesthesiologists Annual Meeting; 2014:A4206.

96. Gross JB, Bachenberg KL, Benumof JL, et al. Practice guidelines for the perioperative management of patients with obstructive sleep apnea: a report by the American Society of Anesthesiologists Task Force on Perioperative Management of patients with obstructive sleep apnea. Anesthesiology. 2006;104(5):1081-1093; quiz 1117-1088.

97. Bonnet MP, Mignon A, Mazoit JX, Ozier Y, Marret E. Analgesic efficacy and adverse effects of epidural morphine compared to parenteral opioids after elective caesarean section: a systematic review. Eur $J$ Pain. 2010;14(9):894.e1-894.e9.

98. McDonnell NJ, Paech MJ, Browning RM, Nathan EA. A randomised comparison of regular oral oxycodone and intrathecal morphine for post-caesarean analgesia. Int J Obstet Anesth. 2010;19(1):16-23.

99. Carvalho B. Respiratory depression after neuraxial opioids in the obstetric setting. Anesth Analg. 2008;107(3):956-961.

100. Crowgey TR, Dominguez JE, Peterson-Layne C, Allen TK, Muir HA, Habib AS. A retrospective assessment of the incidence of respiratory depression after neuraxial morphine administration for postcesarean delivery analgesia. Anesth Analg. 2013;117(6):1368-1370.

101. Practice guidelines for the prevention, detection, and management of respiratory depression associated with neuraxial opioid administration: an updated report by the American Society of Anesthesiologists Task Force on Neuraxial Opioids and the American Society of Regional Anesthesia and Pain Medicine. Anesthesiology. 2016;124(3): 535-552.

102. Mishriky BM, George RB, Habib AS. Transversus abdominis plane block for analgesia after cesarean delivery: a systematic review and meta-analysis. Can J Anaesthesia. 2012;59(8):766-778.

103. Toshniwal G, Soskin V. Ultrasound-guided transversus abdominis plane block in obese patients. Indian JAnaesth. 2012;56(1):104-105.

104. Mirza F, Carvalho B. Transversus abdominis plane blocks for rescue analgesia following cesarean delivery: a case series. Can J Anaesth. 2013;60(3):299-303.
105. Adesope O, Ituk U, Habib AS. Local anaesthetic wound infiltration for post-caesarean analgesia: a systematic review and meta-analysis. Eur J Anaesthesiol. Epub 2016 Jun 2.

106. Chen LK, Lin PL, Lin CJ, et al. Patient-controlled epidural ropivacaine as a post-cesarean analgesia: a comparison with epidural morphine. Taiwan J Obstet Gynecol. 2011;50(4):441-446.

107. Rowe H, Baker T, Hale TW. Maternal medication, drug use, and breastfeeding. Child Adolesc Psychiatr Clin N Am. 2015;24(1): $1-20$.

108. Khan KS, Wojdyla D, Say L, Gülmezoglu AM, Van Look PF. WHO analysis of causes of maternal death: a systematic review. Lancet. 2006;367(9516): 1066-1074.

109. Callaghan WM, Creanga AA, Kuklina EV. Severe maternal morbidity among delivery and postpartum hospitalizations in the United States. Obstet Gynecol. 2012;120(5):1029-1036.

110. Guh DP, Zhang W, Bansback N, Amarsi Z, Birmingham CL, Anis AH. The incidence of co-morbidities related to obesity and overweight: a systematic review and meta-analysis. BMC Public Health. 2009;9:88.

111. Bhattacharya S, Campbell DM, Liston WA, Bhattacharya S. Effect of body mass index on pregnancy outcomes in nulliparous women delivering singleton babies. BMC Public Health. 2007;7:168.

112. Larsen TB, Sørensen HT, Gislum M, Johnsen SP. Maternal smoking, obesity, and risk of venous thromboembolism during pregnancy and the puerperium: a population-based nested case-control study. Thromb Res. 2007;120(4):505-509.

113. Leung TY, Leung TN, Sahota DS, et al. Trends in maternal obesity and associated risks of adverse pregnancy outcomes in a population of Chinese women. Bjog. 2008;115(12):1529-1537.

114. Sebire NJ, Jolly M, Harris JP, et al. Maternal obesity and pregnancy outcome: a study of 287,213 pregnancies in London. Int J Obes Relat Metab Disord. 2001;25(8):1175-1182.

115. Usha Kiran TS, Hemmadi S, Bethel J, Evans J. Outcome of pregnancy in a woman with an increased body mass index. BJOG. 2005;112(6):768-772.

116. Chu SY, Kim SY, Lau J, et al. Maternal obesity and risk of stillbirth: a metaanalysis. Am J Obstet Gynecol. 2007;197(3):223-228.

117. Kristensen J, Vestergaard M, Wisborg K, Kesmodel U, Secher NJ. Pre-pregnancy weight and the risk of stillbirth and neonatal death. BJOG. 2005; 112(4):403-408.

118. Ingrande J, Lemmens HJ. Dose adjustment of anaesthetics in the morbidly obese. Br J Anaesth. 2010;105(Suppl 1):i16-i23.

119. Bates SM, Greer IA, Middeldorp S, Veenstra DL, Prabulos AM, Vandvik PO. VTE, thrombophilia, antithrombotic therapy, and pregnancy. Antithrombotic Therapy and Prevention of Thrombosis, 9th ed. American College of Chest Physicians Evidence-Based Clinical Practice Guidelines. Chest. 2012;141(2 Suppl):e691S-e736S.

120. Royal College of Obstetricians and Gynaecologists. Reducing the Risk of Venous Thromboembolism during Pregnancy and the Puerperium. Green-top guideline number 37a; 2015.

121. James A. Practice bulletin no. 123: thromboembolism in pregnancy. Obstet Gynecol. 2011;118(3):718-729.
Local and Regional Anesthesia

\section{Publish your work in this journal}

Local and Regional Anesthesia is an international, peer-reviewed, open access journal publishing on the development, pharmacology, delivery and targeting and clinical use of local and regional anesthetics and analgesics. The journal is included in PubMed, and welcomes submitted papers covering original research, basic science, clinical studies, reviews and evaluations, guidelines, expert opinion and commentary,
case reports and extended reports. The manuscript management system is completely online and includes a very quick and fair peer-review system, which is all easy to use. Visit http://www.dovepress.com/ testimonials.php to read real quotes from published authors. 